\title{
Sex Differences and the Effects of Modified Combat Regulations on Endurance Capacity in Judo Athletes: A Meta-Analytic Approach
}

\author{
by \\ Katarzyna Sterkowicz-Przybycieñ ${ }^{1}$, David H. Fukuda ${ }^{2}$
}

Judo requires endurance capacity to recover from its high-intensity intermittent actions. This systematic review aimed to evaluate VO2max and the anaerobic threshold in competitive male and female judo athletes. Twelve eligible studies were chosen for quantitative meta-analysis, including results for 188 male and 159 female athletes. Combined values were calculated and compared by gender prior to and following altered combat regulations in 2003. No significant differences in VO2max were noted following the rule changes, but female athletes' values increased to a level comparable to those reported in male athletes prior to the alterations. VO2max in male judo athletes was higher $\left(54.8 \pm 1.9 \mathrm{ml} \cdot \mathrm{kg}^{-1} \cdot \mathrm{min}^{-1}\right)$ than in female athletes $\left(48.7 \pm 2.2 \mathrm{ml} \cdot \mathrm{kg}^{-1} \cdot \mathrm{min}^{-1}\right)$. The effect size of gender was large $(d=1.30)$ for VO2max and negligible for the anaerobic threshold. Sexual dimorphism exists in VO2max of judo athletes and changes in combat duration did not affect these differences.

Key words: performance, aerobic fitness, gender, combat sports.

\section{Introduction}

Judo is an Olympic combat sport that requires endurance capacity to recover from its high-intensity intermittent actions, including throws and grappling techniques, and in response to prolonged competitive bouts and training sessions (Franchini et al., 2011). Endurance capacity is evaluated in athletes by examination of maximal aerobic power (VO2max), usually expressed as the maximum volume of $\mathrm{O} 2$ consumption per minute relative to body mass, or the anaerobic threshold, typically expressed as a percentage of VO2max (Franchini et al., 2011).

During competition, lack of offensive activity results in passivity penalties and the time spent actively attempting to grasp opponents has shown to differ amongst judo athletes of varying competitive levels (Calmet et al., 2010). Comprehensive studies have confirmed that high
VO2max determines the ability to maintain high levels of offensive activity during a judo combat (Lech et al., 2007). Performing moderate-intensity aerobic exercise during breaks between competitive bouts contributes to a more rapid recovery of high-energy substrates and an increased chance of winning (Franchini et al., 2009; Franchini et al., 2011). Although evaluation of VO2max represents one of the elements recommended for monitoring training of judo athletes (Robertson and LaHart, 2009), previous comparisons between male and female judoka have been based on small sample sizes $(n<10)$ and yielded inconsistent results with regard to gender-based differences Callister et al., 1991; Little, 1991; Sbriccoli et al., 2007; Sertic et al., 2006).

In order to account for the possibility of

\footnotetext{
1 - Department of Gymnastics $\mathcal{E}$ Dance, Institute of Sport Sciences, Faculty of Physical Education and Sport, University School of Physical Education, Cracow, Poland.

2 - Institute of Exercise Physiology \& Wellness, University of Central Florida, Orlando, FL.
} 
limited statistical power due to the typically small sample size of investigations in highly competitive judo athletes, a meta-analysis procedure is proposed to examine the combined results of previously reported data from international studies (Thomas et al., 2011). Modifications of judo combat regulations in 2003 (Federation, 2003) increased the fight duration for women from 4 to 5 minutes, and for all athletes, in the event of a draw, the combat would continue until an athlete achieved a score, rather than the winner being decided by referees. These altered regulations might have affected the methodologies of endurance training and consequently improved the level of aerobic power in judo athletes.

Thus, the aims of the study were (1) to find optimum values that would characterize VO2max and the anaerobic threshold of competitive judo athletes, (2) to evaluate changes in $\mathrm{VO} 2 \mathrm{max}$ due to increased combat duration and a new protocol for combats ending in a draw, and (3) to indicate gender-related differences in judo athletes.

\section{Material and Methods}

\section{Measures/Procedures}

The keywords "judo", "male", "female", "aerobic", and "anaerobic threshold" were utilized to search for appropriate publications in research databases, including Academic Search Complete, SPORTDiscus with full text, MEDLINE and Google Scholar, from their inception until December 2014. Furthermore, selected publications not identified through the database search were included at the discretion of the authors.

All publications were then screened using the following inclusion/exclusion criteria prior to quantitative analysis: (a) the sample of athletes possessed sufficient experience and skill to be considered highly competitive in the senior classification, varying from provincial teams to Olympic-level athletes; (b) results for both men and women were reported; and (c) the results of the research contained, at minimum, the following statistics for $\mathrm{VO} 2$ max: sample size $(n)$, mean and standard deviation $(S D)$.

The included publications were divided with regard to the publication date [pre-2003 for men (M1) and women (F1); post-2003 for men
(M2) and women (F2)] in order to compare any possible differences in $\mathrm{VO} 2 \mathrm{max}$ after changes in the rules resulting in longer combat duration for women and new procedures for combats resulting in a draw.

\section{Analysis}

The combined means and standard deviations for anthropometric values, $\mathrm{VO} 2$ max, and the anaerobic threshold were calculated according to the equations recommended by Kirkendall et al. (1987):

$$
\begin{aligned}
& \text { Combtred } \bar{x}=\frac{\sum\left(x_{i} \cdot n_{i}\right)}{\Sigma\left(x_{t}\right.} \\
& \text { Combtned SD }=\sqrt{\frac{\sum\left(m_{i}, S D_{i}^{2}\right)}{\sum m_{l}}}
\end{aligned}
$$

(Hquation 1)

Where: $\bar{x}_{i}$ is the mean value for a sample, $n_{i}$ is a sample size for a sample, and $S D_{\mathrm{i}}$ is the standard deviation for a given sample.

For interpretation of intergroup differences, independent samples t-tests were utilized and a significance level of $p<0.05$ was adopted. These differences were further examined based on Cohen's d effect size with 95\% confidence intervals and interpreted as small $(\leq 0.2)$, moderate $(0.5-0.8)$, or large $(>0.8)$. Forest plots were generated with a data analysis software system (STATISTICA version 10, StatSoft, Inc.) and used for graphical illustration of differences between individual studies and overall outcomes.

\section{Results}

\section{Literature Search Findings}

The results of the literature search are illustrated in Figure 1. The initial search of international databases and other sources identified 33 records using the keywords and manual searching techniques which were considered for qualitative analysis. During the screening stage, 21 records were excluded as they did not meet the inclusion criteria and the remaining 12 eligible studies were included for quantitative meta-analysis. The included studies contained 22 individual samples of competitive male $(n=188)$ and female $(n=159)$ senior judo athletes.

Qualitative Analysis

Only observational, cross-sectional 
studies were found. The sample sizes of studies ranged between 6 - 75 in male and 5 - 67 in female groups. The authors did not report the reliability of testing methods used. Body height and mass data were not presented in one study (Sertic et al., 2006). Based on the available data, the body mass index (BMI) was calculated, with values from individual studies ranging from 23.3 to $33.6 \mathrm{~kg} \cdot \mathrm{m}^{-2}$ in men and from 21.6 to $25.6 \mathrm{~kg} \cdot \mathrm{m}^{-2}$ in women. In men, all the cohorts, except for Spanish athletes (Santos et al., 2011) were considered overweight compared to the international standard of BMI > $25 \mathrm{~kg} \cdot \mathrm{m}^{-2}$ (Cole et al., 2000), whereas among women, the overweight athletes were found only in the group of Koreans (Kim et al., 1996). Male body fat content (BF\%) ranged from 8.3 to $14.5 \%$, whereas in women, this value ranged from 12.4 to $20.6 \%$, but was not reported in four samples.
Further exploration of body composition values was precluded due to lack of the reported data (Borkowski et al., 2001; Ebine et al., 1991; Laskowski et al., 2008; Sbriccoli et al., 2007). Notably, heavyweights often possessed a fat-free mass index with values over $25 \mathrm{~kg} \cdot \mathrm{m}^{-2}$ (Sterkowicz-Przybycien and Almansba, 2011). Quantitative Analysis

Athletes' Characteristics

The 182 male athletes (mean \pm SD; $23.2 \pm$ 2.8 yrs; $176.6 \pm 7.7 \mathrm{~cm} ; 82.6 \pm 15.4 \mathrm{~kg}$ ) for whom data were reported were older $(\mathrm{t}=9.856 ; p<0.001)$, taller ( $\mathrm{t}=15.292 ; p<0.001)$, and heavier $(\mathrm{t}=12.792$; $p<0.001$ ) than the 151 female athletes (mean \pm SD; $20.4 \pm 2.5$ years; $164.7 \pm 6.5 \mathrm{~cm} ; 63.6 \pm 12.3 \mathrm{~kg}$ ) for whom data were reported.

Table 1

\begin{tabular}{cccc}
\multicolumn{4}{c}{ Maximal aerobic power (VO2max) of senior male and female judo competitors } \\
\hline Author (year) & Country Male & Female
\end{tabular}

\begin{tabular}{lllll}
\hline $\mathrm{n}$ & Mean & SD & M & Mean
\end{tabular}

\begin{tabular}{lllllllll}
\hline Callister et al. (1990) & USA & 8 & 53.2 & 1.4 & 7 & 51.9 & 0.8 & Treadmill \\
Callister et al. (1991) & USA & 18 & 55.6 & 1.8 & 9 & 52.0 & 1.4 & Treadmill \\
Ebine et al. (1991) & Japan & 13 & 45.9 & 4.8 & 16 & 42.1 & 4.4 & Treadmill \\
Little (1991) & Canada & 17 & 53.8 & 5.6 & 8 & 43.7 & 3.5 & Treadmill \\
Kim (1996) & Korea & 10 & 62.8 & 5.9 & 10 & 50.5 & 6.9 & NC \\
Borkowski et al. (2001) & Poland & 75 & 56.6 & 5.6 & 67 & 49.9 & 6.6 & Bicycle \\
Sertic et al. (2006) & Croatia & 6 & 58.7 & 2.6 & 8 & 47.7 & 5.3 & NC \\
Sbriccoli et al. (2007) & Italy & 6 & 47.3 & 10.9 & 5 & 52.9 & 4.4 & Treadmill \\
Laskowski et al. (2008) & Poland & 20 & 57.6 & 2.3 & 15 & 51.2 & 4.3 & Ergocycle \\
Almansba et al. (2010a) & Algeria & 7 & 50.6 & 9.3 & 6 & 50.7 & 6.0 & PWC170 \\
Santos et al. (2011, 2012)a,b & Spain & 8 & 52.8 & 7.9 & 8 & 40.9 & 7.7 & Treadmill \\
\hline
\end{tabular}

${ }^{a}$ data of males published in 2011; ${ }^{b}$ data of females published in 2012. Abbreviations: SD - standard deviation, PWC - physical working capacity, NC - not communicated. 


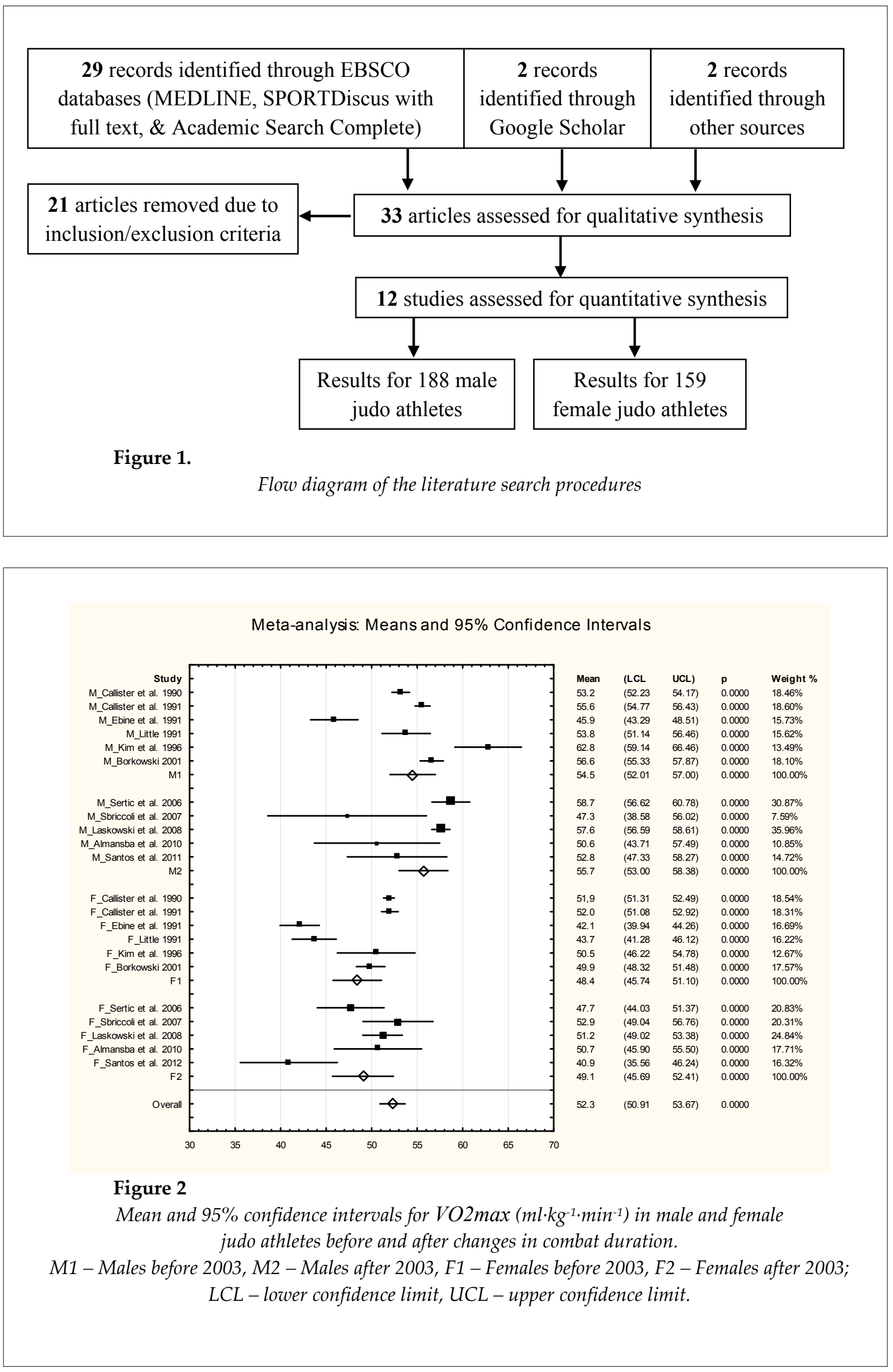




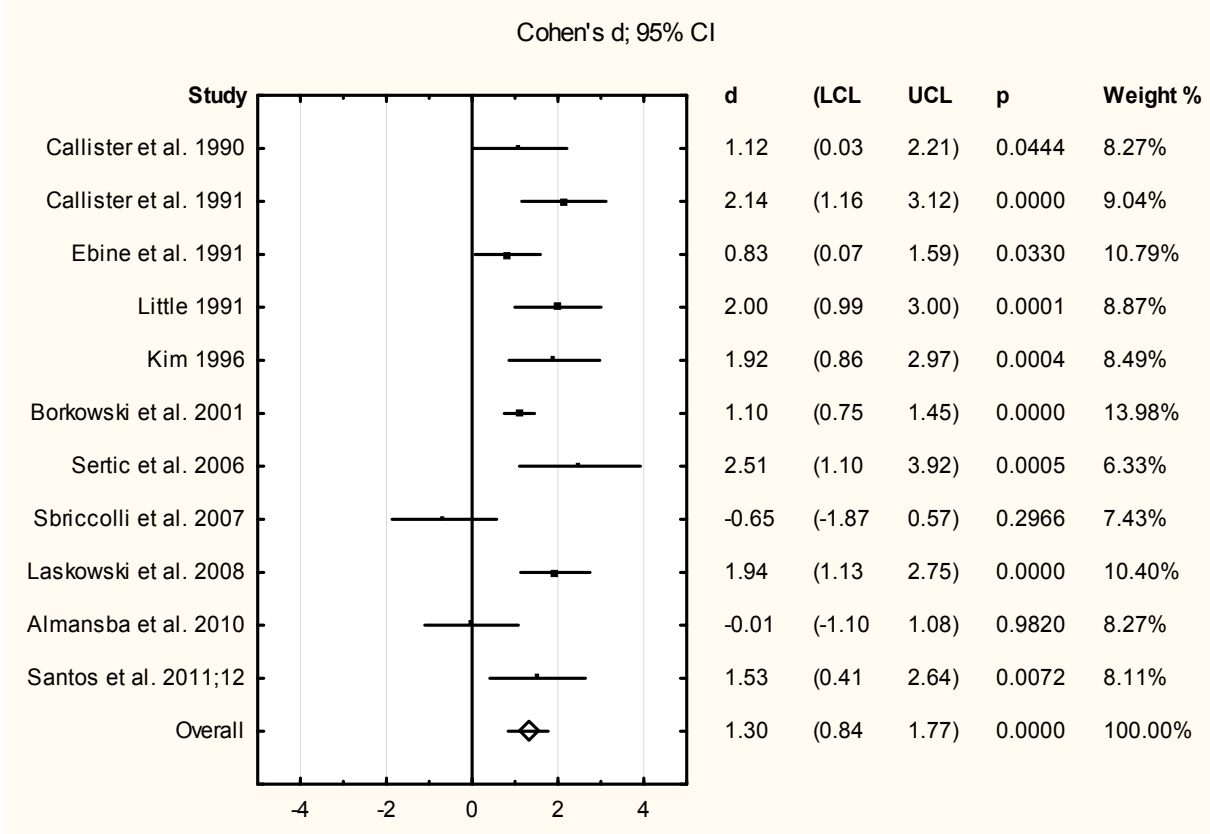

Figure 3.

Forest plot of comparison of effect sizes (Cohen's d) and 95\% confidence intervals (95\% CI) between VO2 max of male and female athletes.

$L C L$ - lower confidence limit, UCL - upper confidence limit.

\section{Maximal Aerobic Power (VO2max)}

To avoid the effect of body mass in this study, the analyzed results were relative to body mass for both $\mathrm{VO} 2 \mathrm{max}$ and the anaerobic threshold. The results for $\mathrm{VO} 2 \mathrm{max}$ are presented and compared in Table 1. Relative VO2max levels in men ranged from 45.9 (Ebine et al., 1991) to 62.8 $\mathrm{ml} \cdot \mathrm{kg}^{-1} \cdot \mathrm{min}^{-1}$ (Kim et al., 1996), whereas these values in women ranged from 40.9 (Santos et al., 2012) to $52.9 \mathrm{ml} \cdot \mathrm{kg}^{-1} \cdot \mathrm{min}^{-1}$ (Sbriccoli et al., 2007). Figure 2 provides a graphic representation of differences between 22 individual coded samples of male and female judo athletes.

A nonsignificant increase in relative VO2max was observed after 2003 in men (M2) and women (F2) compared to the period before 2003 (M1/F1). However, the VO2max values in women after the aforementioned rule changes (F1) were not significantly different from men's values prior to the altered combat regulations
(M2) $(p>0.05)$. Meta-analysis of the combined data showed that the mean value of $\mathrm{VO} 2 \mathrm{max}$ was higher in men $\left(54.8, \mathrm{CL}=52.9 ; 56.7 \mathrm{ml} \cdot \mathrm{kg}^{-1} \cdot \mathrm{min}^{-1}\right)$ compared to women $(48.7, \mathrm{CL}=46.48 ; 50.70 \mathrm{ml} \cdot \mathrm{kg}$ $\left.{ }^{1} \cdot \mathrm{min}^{-1}\right)$.

Figure 3 shows the comparison of VO2max between genders. The overall effect size between men and women was large $(\mathrm{d}=1.30)$, but there was moderate heterogeneity between individual studies with an $\mathrm{I}^{2}$ statistic of $64.8 \%$ (95\% CL $=33.0 ; 81.5)$. Effect size was large $(>0.8)$ in 9 of the examined individual studies of male and female athletes. Results of samples from Italy (Sbriccoli et al., 2007) and Algeria (Almansba et al., 2010a) were unique in presented situations in which relative $\mathrm{VO}_{2 \max }$ was higher, though not significantly $(p>0.05)$, in women compared to men.

Anaerobic Threshold (\%VO2max)

The anaerobic threshold (\%VO2max), 
which was measured in six individual studies (Callister et al., 1991; Ebine et al., 1991; Kim et al., 1996; Little, 1991; Santos et al., 2011; Santos et al., 2012; Sbriccoli et al., 2007), did not differ between male $(77.2 \%, C L=76.98 ; 77.48 \%)$ and female (76.6\%, CL $=76.00 ; 77.26 \%$ ) judo athletes.

\section{Discussion}

The primary finding of the meta-analysis was the confirmation of differences in $\mathrm{VO}_{2 \max }$ between male and female judo athletes. Apart from a trend towards increased $\mathrm{VO} 2 \mathrm{max}$ following the modification of IJF rules in 2003 and values in women that were comparable to prior values seen in men, no significant changes were observed between the two time periods. Additionally, gender-based differences were not apparent in the anaerobic threshold and did not differ between men and women.

A comparison of the descriptive data between senior judo athletes revealed that male athletes were taller and heavier than female ones. Higher body mass, which is usually accompanied by higher BF\% (Sterkowicz-Przybycien and Almansba, 2011), has been known to limit relative aerobic power in heavy weight categories (Borkowski et al., 2001). In our systematic review, $\mathrm{BF} \%$ and the anaerobic threshold were only reported for a fraction of male (38.8\%) and female $(35.2 \%)$ athletes. Men typically had lower adiposity than women, which may be partially explained by the reported sex $\mathrm{x}$ weight interaction for VO2max in Italian and Algerian Olympic teams, where the women were recruited from lighter weight categories $(63.8 \mathrm{~kg}$ and $65.5 \mathrm{~kg}$, respectively) and men from heavier categories (109.0 kg and $91.85 \mathrm{~kg}$, respectively) (Almansba et al., 2010a; Sbriccoli et al., 2007).

Due to the disparity amongst individual studies and large variability in the reported data for VO2max (Figure 2), a meta-analysis was the most appropriate approach to evaluate sex-based differences, whereas a simple review of literature may have resulted in contradictory observations. As previously indicated, the non-significant improvement in VO2max by women after 2003 resulted in values comparable to pre-2003 values in men, however, the conclusion that this equivalence in reported values was strictly attributed to the rules modifications cannot be fully confirmed. The intergroup comparisons showed a trend toward increased $\mathrm{VO} 2 \mathrm{max}$ in male and female judo athletes after 2003, but with potentially greater improvements in men. This suggests the influence of lower adaptive changes in endurance capacity by female judo athletes in response to increased demands of athletic training and competition following the change in combat duration. However, this conclusion should be interpreted with caution due to the nonsignificant changes in VO2max observed in male and female athletes for the periods selected. Furthermore, testing modality and methodology may contribute to the variability amongst studies. The use of VO2max as a physiological index for determination of endurance performance of judo athletes has been questioned (Almansba et al., 2010b; Borkowski et al., 2001). However, Lech et al. (2007) reported a significant inverse correlation between relative $\mathrm{VO} 2 \mathrm{max}$ and changes in offensive activity during competitive bouts suggesting that higher aerobic capacity may be related to maintenance of effort and/or attacking ability.

The advantage of this meta-analysis is the generalization of the results obtained for $\mathrm{VO} 2 \mathrm{max}$ and the anaerobic threshold that characterize the endurance capacity of male and female judo athletes. When genders are compared, females reach approximately $89.1 \%$ of male $\mathrm{VO} 2 \mathrm{max}$ values. Despite these differences in maximal aerobic power, the results of the current investigation show that the relative anaerobic threshold (\%VO2max) was similar in male and female judo athletes. Regardless of sex, judo fighting requires great demands on both the aerobic (Thomas et al., 1989) and anaerobic (Pulkkinen, 2001) energy systems. Intensive actions while performing judo throws depend on high alactic contribution, whereas glycolytic contribution dominates during prolonged sequences of exercise (Franchini et al., 2011; Obmiński et al., 2008). Regardless of gender, comprehensive development of the three energy systems i.e. aerobic, alactic and lactic, is necessary for success in competition (Franchini et al., 2011; Obmiński et al., 2008). In support, similar timemotion structures have been observed during competition for men and women (Van Malderen et al., 2006).

Few studies have examined the changes in $\mathrm{VO}_{2 \max }$ and the anaerobic threshold during 
periods of judo training. Some findings suggest that it is not necessary to repeat $\mathrm{VO}_{2 \max }$ measurements throughout the training process (Almansba et al., 2010b), while others have reported only non-significant changes in these variables following six weeks of training before competition (Sterkowicz et al., 2012). However, the adoption of individual indices of endurance capacity as general performance indicators without previous determination of their relationship with judo-specific performance (effort:pause ratios, scoring ability, etc.) in competition is insufficient (Lech et al., 2007). For example, Detanico et al. (2012) showed negative correlations between glycolytic activity during the fight and the anaerobic threshold. Gender-specific response to competitive judo combats have been previously demonstrated with blood lactate concentration after competitive bouts reported to be typically higher in men compared to women and correlated with the duration of the fight (Obmiński et al., 2008).

Further research is needed to establish the relationships between aerobic and anaerobic capacity in men and women during activities related to judo practice and competition. This research direction is of particular importance considering that recently the International Judo Federation reversed the 2003 rule change and again implemented a 4 min combat duration for senior women (Federation, 2014). With limited fight duration, an increase in offensive activity may occur and alterations in endurance capacity of female judo athletes could be expected. The primary limitation of this study was the specific focus on endurance capacity as an indicator of conditioning in judo athletes. Indeed, there are numerous other factors potentially influencing judo performance and athlete readiness, including the anaerobic metabolism and both psychological and emotional factors.

\section{Conclusion}

The broad range of relative VO2max levels in the group of men and women indicates existence of opportunities for compensation of lower maximal aerobic power by higher levels in technical and tactical factors. After the fight duration for women and the procedures for a draw were changed in the judo regulations in 2003, a tendency for increased $\mathrm{VO} 2 \mathrm{max}$ was observed. A large overall effect size between men and women for VO2max of highly competitive judo athletes and only a small effect for the anaerobic threshold were found. Therefore, sexual dimorphism for endurance capacity differs between these parameters.

\section{References}

Almansba R, Sterkowicz S, Belkacem R, Sterkowicz-Przybycien K, Mahdad D. (a) Anthropometrical and physiological profiles of the Algerian Olympic judoists. Arch Budo, 2010; 6: 185-193

Almansba R, Sterkowicz S, Sterkowicz-Przybycien K, Belkacem R. (b) Maximal oxygen uptake changes during judoist's periodization training. Arch Budo, 2010; 6: 117-122

Borkowski L, Faff J, Starczewska-Czapowska J. Evaluation of the aerobic and anaerobic fitness in judoists from the Polish National Team. Biol Sport, 2001; 18: 107-117

Callister R, Callister RJ, Fleck SJ, Dudley GA. Physiological and Performance Responses to Overtraining in Elite Judo Athletes. Med Sci Sport Exer, 1990; 22: 816-824

Callister R, Callister RJ, Staron RS, Fleck SJ, Tesch P, Dudley GA. Physiological-Characteristics of Elite Judo Athletes. Int J Sports Med, 1991; 12: 196-203

Calmet M, Miarka B, Franchini E. Modeling of grasps in judo contests. Int J Perf Anal Spor, 2010; 10: 229-240

Cole TJ, Bellizzi MC, Flegal KM, Dietz WH. Establishing a standard definition for child overweight and obesity worldwide: international survey. Brit Med J, 2000; 320: 1240-1243

Detanico D, Dal Pupo J, Franchini E, dos Santos SG. Relationship of aerobic and neuromuscular indexes with specific actions in judo. Sci Sport, 2012; 27: 16-22

Ebine K, Yoneda I, Hase H, Aihara K, Aihara M, Akaike M, Ishida H, Nishimoto K, Nomura M, Tsuda H. Physiological characteristics of exercise and findings of laboratory tests in Japanese elite judo athletes. Médecine du Sport, 1991; 65: 245-249 
Franchini E, Bertuzzi RCD, Takito MY, Kiss MAPDM. Effects of recovery type after a judo match on blood lactate and performance in specific and non-specific judo tasks. Eur J Appl Physiol, 2009; 107: 377-383

Franchini E, Sterkowicz S, Szmatlan-Gabrys U, Gabrys T, Garnys M. Energy System Contributions to the Special Judo Fitness Test. Int J Sport Physiol, 2011; 6: 334-343

International Judo Federation. IJF Refereeing Rules; 2003

International Judo Federation. IJF Refereeing Rules; 2014

Kim KJ, Kim EH, Han MW. A comparison of physiological and performance responses for analysis of the degree of judo training intensity. Korean J Sport Sci, 1996; 8: 52-64

Kirkendall DR, Gruber JJ, Johnson RE. Measurement and Evaluation for Physical Educators. 2nd ed. Champaign, Ill.: Human Kinetics Publishers, xviii, 553; 1987

Laskowski R, Wysocki K, Multan A, Haga S. Changes in cardiac structure and function among elite judoists resulting from long-term judo practice. J Sport Med Phys Fit, 2008; 48: 366-370

Lech G, Tyka A, Pałka T, Krawczyk R. The physical efficiency and the course of fights and the sports level of judo contestants. Medicina Sportiva Practica, 2007; 8: 81-85

Little NG. Physical Performance Attributes of Junior and Senior Women, Juvenile, Junior, and Senior Men Judokas. J Sport Med Phys Fit, 1991; 31: 510-520

Obmiński Z, Borkowski L, Starczewska-Czapowska J. Capillary blood lactate levels after judo matches in male and female competitors. Gender related differences. Medycyna Sportowa, 2008; 3: 171-176

Pulkkinen WJ. The Sport Science of Elite Judo Athletes: A Review and Application For Training: Pulkinetics; 2001

Robertson $\mathrm{P}$, LaHart I. The design of a judo-specific strength and conditioning programme. Journal of Sports Therapy, 2009; 3: 1-5

Santos L, Gonzalez V, Iscar M, Brime JI, Fernandez-Rio J, Rodriguez B, Montoliu MA. Retesting The Validity Of A Specific Field Test For Judo Training. J Hum Kinet, 2011; 29: 141-150

Santos L, Gonzalez V, Iscar M, Brime JI, Fernandez-Rio J, Rodriguez B, Montoliu MA. Physiological response of high-level female judokas measured through laboratory and field tests. Retesting the validity of the Santos test. J Sport Med Phys Fit, 2012; 52: 237-244

Sbriccoli P, Bazucchi I, Di Mario A, Marzattinocci G, Felici F. Assessment of maximal cardiorespiratory performance and muscle power in the Italian Olympic judoka. J Strength Cond Res, 2007; 21: 738-744

Sertic H, Segedi I, Milanovic D. Anthropological and fitness status of Croatian judoists. Arch Budo, 2006; 2: 24-27

Sterkowicz-Przybycien K, Almansba R. Sexual dimorphism of anthropometrical measurements in judoists vs untrained subject. Sci Sport, 2011; 26: 316-323

Sterkowicz S, Tyka AK, Chwastowski M, Sterkowicz-Przybycien K, Tyka A, Klys A. The effects of training and creatine malate supplementation during preparation period on physical capacity and special fitness in judo contestants. J Int Soc Sport Nutr, 2012; 9: 1-8

Thomas JR, Nelson JK, Silverman SJ. Research methods in physical activity. 6th ed. Champaign, IL: Human Kinetics, xiii, 457; 2011

Thomas SG, Cox MH, Legal YM, Verde TJ, Smith HK. Physiological Profiles of the Canadian National Judo Team. Can J Sport Sci, 1989; 14: 142-147

Van Malderen K, Jacobs C, Ramon K, Evert Z, Deriemaeker P, Clarys P. Time and technique analysis of a judo fight: a comparison between males and females. In: Hopeler $\mathrm{H}$, ed. 11th Annual Congress of the European College of Sport Science. Lausanne, Switzerland, 101; 2006

\section{Corresponding author: \\ David H. Fukuda}

Institute of Exercise Physiology and Wellness, University of Central Florida

Orlando, Florida, USA

Phone: +1 (407) 823-0442 ; E-mail: david.fukuda@ucf.edu 